\title{
Existence of Positive Periodic Solutions for a Class of Higher-Dimension Functional Differential Equations with Impulses
}

\author{
Zhang Suping ${ }^{1,2}$ and Jiang Wei $^{1}$ \\ ${ }^{1}$ School of Mathematical Science, Anhui University, Hefei, Anhui 230039, China \\ ${ }^{2}$ Department of Mathematics and Physics, Anhui Jianzhu University, Hefei, Anhui 230601, China \\ Correspondence should be addressed to Zhang Suping; zsp606@163.com
}

Received 3 August 2013; Accepted 1 October 2013

Academic Editor: Youyu Wang

Copyright (C) 2013 Z. Suping and J. Wei. This is an open access article distributed under the Creative Commons Attribution License, which permits unrestricted use, distribution, and reproduction in any medium, provided the original work is properly cited.

By employing the Krasnoselskii fixed point theorem, we establish some criteria for the existence of positive periodic solutions of a class of $n$-dimension periodic functional differential equations with impulses, which improve the results of the literature.

\section{Introduction}

Some evolution processes are distinguished by the circumstance that the evolutions change very rapidly at certain instants. In mathematical simulations, impulsive delay differential equations may express several simulation processes in real world which depend on their prehistory and are subject to short time disturbances. Such processes occur in the theory of optional control, population dynamics, biotechnologies, economics, and so forth. In recent years, the existence theory of positive periodic solutions of delay differential equations with impulsive effects or without impulsive effects has been an object of active research; we refer the reader to [1-4]. For other related works on studying for impulsive delay differential equations, we refer the reader to [5-7].

In [8], Zeng et al. studied the following functional differential equations without impulses:

$$
\dot{x}(t)=A(t, x(t)) x(t)+\lambda f\left(t, x_{t}\right),
$$

and obtained sufficient conditions for the existence of positive periodic solutions of (1).

Zhang et al. [9] investigated the following form:

$$
\begin{gathered}
\dot{x}(t)=A(t) x(t)+f\left(t, x_{t}\right), \quad t \neq \tau_{k}, k \in Z_{+}, \\
\left.\Delta x\right|_{t=\tau_{k}}=I_{k}\left(x\left(\tau_{k}\right)\right) .
\end{gathered}
$$

In this paper, we will consider the $n$-dimension differential equation with impulses as follows:

$$
\begin{gathered}
\dot{x}(t)=A(t, x(t)) x(t)+\lambda f\left(t, x_{t}\right), \quad t \neq \tau_{k}, k \in Z_{+}, \\
\left.\Delta x\right|_{t=\tau_{k}}=I_{k}\left(x\left(\tau_{k}\right)\right),
\end{gathered}
$$

where $\lambda>0$ is a parameter, $A(t, x(t))=\operatorname{diag}\left[a_{1}(t, x(t)), a_{2}(t\right.$, $\left.x(t)), \ldots, a_{n}(t, x(t))\right], a_{i} \in C(R \times R, R)$ is $\omega$-periodic, and $f\left(t, x_{t}\right)$ is an operator defined on $R \times B C\left(R, R^{n}\right)$ (here $B C\left(R, R^{n}\right)$ denotes the Banach space of bounded continuous operator $\phi: R \rightarrow R^{n}$ with the norm $\|\phi\|=$ $\sum_{i=1} \sup _{\theta \in R}\left|\phi_{i}(\theta)\right|$, where $\left.\phi=\left(\phi_{1}, \phi_{2}, \ldots, \phi_{n}\right)^{T}\right)$. For $x \in B C$ and $t \in R, x_{t} \in B C$ is defined by $x_{t}(\theta)=x(t+\theta)$ for $\theta \in R$ (see [10], Zheng). Consider that $f\left(t+\omega, x_{t}\right)=f\left(t, x_{t}\right)$ and $\left.\Delta x\right|_{t=\tau_{k}}=x\left(\tau_{k}^{+}\right)-x\left(\tau_{k}\right)$ (here $x\left(\tau_{k}^{+}\right)$represents the right limit of $x$ at the point $\left.\tau_{k}\right), I_{k}=\left(I_{k}^{1}, I_{k}^{2}, \ldots, I_{k}^{n}\right) \in C\left(R_{+}^{n}, R_{-}^{n}\right)$, that is, $x$ changes decreasingly suddenly at $\tau_{k}, \omega>0$ is a constant, $R_{+}$and $R_{-}$are the sets of all nonnegative and nonpositive real numbers, respectively. We assume that there exists an integer $p>0$ such that $\tau_{k+p}=\tau_{k}+\omega, I_{k+p}=I_{k}$, where $0<\tau_{1}<\tau_{2}<\cdots<\tau_{p}<\omega$.

\section{Some Preliminaries}

$P C\left(J, R^{n}\right)=\left\{\phi: J \rightarrow R^{n}, \phi\right.$ is continuous everywhere except at a finite number of points $\tau_{k}$ at which $\phi\left(\tau_{k}^{+}\right)$and $\phi\left(\tau_{k}^{-}\right)$exist 
and $\left.\phi\left(\tau_{k}^{-}\right)=\phi\left(\tau_{k}\right)\right\}, J \subset R$. For each $x=\left(x_{1}, x_{2}, \ldots, x_{n}\right)^{T} \in$ $R^{n}$, the norm of $x$ is defined as $|x|=\sum_{i=1}\left|x_{i}\right|$. tions:

Throughout the paper, we make the following assump-

$\left(H_{1}\right) f\left(t, \varphi_{t}\right) \leq 0$ for all $(t, \varphi) \in R \times B C\left(R, R_{+}^{n}\right)$;

$\left(H_{2}\right) f_{i}\left(t, \varphi_{t}\right)$ is a continuous function of $t$ for each $\varphi \in$ $B C\left(R, R_{+}^{n}\right), i=1,2, \ldots, n$;

$\left(H_{3}\right)$ for any $L>0$ and $\epsilon>0$, there exists $\delta>0$ such that for $\phi, \psi \in B C\left(R, R_{+}^{n}\right),\|\phi\| \leq L,\|\psi\| \leq L$, and $\|\phi-\psi\| \leq \delta$ imply that

$$
\left|f_{i}\left(t, \phi_{t}\right)-f_{i}\left(t, \psi_{t}\right)\right|<\epsilon, \quad \forall t \in[0, \omega], i=1,2, \ldots, n .
$$

To conclude this section, we summarize in the following a few concepts and results that will be needed in our arguments.

Definition 1. Let $X$ be a Banach space, and let $P$ be a closed, nonempty subset of $X$; $P$ is a cone if

(i) $\alpha x+\beta x \in P$ for all $x, y \in P$ and all $\alpha, \beta \geq 0$;

(ii) $x,-x \in P$ imply $x=0$.

Let $X=\left\{x=\left(x_{1}(t), x_{2}(t), \ldots, x_{n}(t)\right)^{T} \in P C\left(R, R^{n}\right) \mid\right.$ $x(t+\omega)=x(t)\}$ with the norm $\|x\|=\sum_{i=1}\left|x_{i}\right|_{0}$, where $\left|x_{i}\right|_{0}=$ $\sup _{t \in[0, \omega]}\left|x_{i}(t)\right|$; then $X$ is a Banach space. then

If $x(t)=\left(x_{1}(t), x_{2}(t), \ldots, x_{n}(t)\right)^{T} \in X$ is a solution of (3),

$$
\begin{aligned}
x_{i}(t)= & \lambda \int_{t}^{t+\omega} G_{i}(t, u) f_{i}\left(u, x_{u}\right) d u \\
& +\sum_{j=1}^{j=p} G_{i}\left(t, \tau_{m_{j}}+n \omega\right) I_{j}^{i}\left(x\left(\tau_{m_{j}}\right)\right),
\end{aligned}
$$

where

$$
G_{i}(t, u)=\frac{\exp \left(-\int_{t}^{u} a_{i}(s, x(s)) d s\right)}{\exp \left(-\int_{0}^{\omega} a_{i}(s, x(s)) d s\right)-1}, \quad i=1,2, \ldots, n .
$$

See [9], Zhang et al.

It is clear that $G_{i}(t+\omega, u+\omega)=G_{i}(t, u)$, for all $(t, u) \in R^{2}$, and by $\left(H_{1}\right)$,

$$
G_{i}(t, u) f_{i}\left(u, \varphi_{u}\right) \geq 0
$$

for $(t, u) \in R^{2}$ and $(u, \varphi) \in R \times B C\left(R, R_{+}^{n}\right)$.

Define for $i=1,2, \ldots, n$,

$$
\begin{gathered}
A_{i}:=\min _{0 \leq t \leq u \leq \omega}\left|G_{i}(t, u)\right|=\frac{\exp \left(-\int_{0}^{\omega} a_{i}(s, x(s)) d s\right)}{1-\exp \left(-\int_{0}^{\omega} a_{i}(s, x(s)) d s\right)}, \\
B_{i}:=\max _{0 \leq t \leq u \leq \omega}\left|G_{i}(t, u)\right|=\frac{1}{1-\exp \left(-\int_{0}^{\omega} a_{i}(s, x(s)) d s\right)}, \\
A:=\min _{1 \leq i \leq n} A_{i}, \quad B:=\max _{1 \leq i \leq n} B_{i} .
\end{gathered}
$$

Let

$$
\begin{gathered}
K=\left\{x(t)=\left(x_{1}(t), x_{2}(t), \ldots, x_{n}(t)\right)^{T} \in X: x_{i}(t) \geq \sigma\left|x_{i}\right|_{0},\right. \\
i=1,2, \ldots, n\},
\end{gathered}
$$

where $\sigma=A / B \in(0,1)$. It is not difficult to verify that $K$ is a cone in $X$. We define an operator $\Phi: X \rightarrow X$ as follows:

$$
(\Phi x)(t)=\left(\left(\Phi_{1} x\right)(t),\left(\Phi_{2} x\right)(t), \ldots,\left(\Phi_{n} x\right)(t)\right)^{T},
$$

where

$$
\begin{aligned}
\left(\Phi_{i} x\right)(t)= & \lambda \int_{t}^{t+\omega} G_{i}(t, u) f_{i}\left(u, x_{u}\right) d u \\
& +\sum_{j=1}^{j=p} G_{i}\left(t, \tau_{m_{j}}+n \omega\right) I_{j}^{i}\left(x\left(\tau_{m_{j}}\right)\right) .
\end{aligned}
$$

Then, it can be immediately obtained from the assumptions $\left(\mathrm{H}_{2}\right)$ and $\left(\mathrm{H}_{3}\right)$ that the operator $\Phi$ is completely continuous. On the other hand, it is not difficult to check that $x^{*}(t)=$ $\left(x_{1}^{*}(t), x_{2}^{*}(t), \ldots, x_{n}^{*}(t)\right)^{T}$ is a positive $\omega$-periodic solution of (3) if and only if $x^{*}(t)$ is a fixed point of the operator $\Phi$.

Before stating the main results, we shall give some important lemmas.

Lemma 2. The mapping $\Phi$ maps $K$ into $K$, that is, $\Phi K \subset K$.

Proof. For any $x \in K$, it is easy to see that $\Phi x \in X$. From (11), we have

$$
\begin{aligned}
\left|\left(\Phi_{i} x\right)\right|_{0} \leq & \lambda B_{i} \int_{0}^{\omega}\left|f_{i}\left(u, x_{u}\right)\right| d u \\
& +B_{i} \sum_{j=1}^{j=p}\left|I_{j}^{i}\left(x\left(\tau_{m_{j}}\right)\right)\right| .
\end{aligned}
$$

Noting that $G_{i}(t, u) f_{i}\left(u, x_{u}\right) \geq 0$, we can also obtain

$$
\begin{aligned}
\left(\Phi_{i} x\right)(t) & \geq \lambda A_{i} \int_{0}^{\omega}\left|f_{i}\left(u, x_{u}\right)\right| d u+A_{i} \sum_{j=1}^{j=p}\left|I_{j}^{i}\left(x\left(\tau_{m_{j}}\right)\right)\right| \\
& \geq \frac{A_{i}}{B_{i}}\left|\left(\Phi_{i} x\right)\right|_{0} \\
& \geq \sigma\left|\left(\Phi_{i} x\right)\right|_{0} .
\end{aligned}
$$

Hence, $\Phi K \subset K$. The proof is complete.

Lemma 3. Let $X$ be a Banach space, and let $K$ be a cone in $X$. Suppose that $\Omega_{1}$ and $\Omega_{2}$ are open subsets of $X$ such that $0 \in \Omega_{1} \subset \overline{\Omega_{1}} \subset \Omega_{2}$. Suppose that

$$
\Phi: K \cap\left(\overline{\Omega_{2}} \backslash \Omega_{1}\right) \longrightarrow K
$$

is a completely continuous operator and satisfies either 
(1)

$$
\begin{aligned}
\|\Phi u\| \leq\|u\|, \quad \forall u \in K \cap \partial \Omega_{1} ; \\
\|\Phi u\| \geq\|u\|, \quad \forall u \in K \cap \partial \Omega_{2} ;
\end{aligned}
$$

or

(2)

$\|\Phi u\| \leq\|u\|, \quad \forall u \in K \cap \partial \Omega_{2} ;$

$\|\Phi u\| \geq\|u\|, \quad \forall u \in K \cap \partial \Omega_{1}$.

Then, $\Phi$ has a fixed point in $K \cap\left(\overline{\Omega_{2}} \backslash \Omega_{1}\right)$.

The proof of Lemma 3 can be found in [11], Guo et al.

Lemma 4. Assume that $\left(H_{1}\right)-\left(H_{3}\right)$ hold and there exists $\eta>0$, such that

$$
\int_{0}^{\omega}\left|f\left(s, \phi_{s}\right)\right| d s \geq \eta\|\phi\|, \quad \text { for } \phi \in K .
$$

Then,

$\|\Phi x\| \geq \lambda A \eta\|x\|$

Proof. If $x \in K$, then

$$
\begin{aligned}
&\left(\Phi_{i} x\right)(t) \geq \lambda A_{i} \int_{t}^{t+\omega}\left|f_{i}\left(u, x_{u}\right)\right| d u \\
&+A_{i} \sum_{j=1}^{j=p}\left|I_{j}^{i}\left(x\left(\tau_{m_{j}}\right)\right)\right| \\
& \geq \lambda A_{i} \int_{t}^{t+\omega}\left|f_{i}\left(u, x_{u}\right)\right| d u .
\end{aligned}
$$

Thus, we have

$$
\begin{aligned}
\|\Phi x\| & =\sup _{t \in R} \sum_{i=1}\left|\left(\Phi_{i} x\right)(t)\right| \\
& \geq \sum_{i=1} \lambda A_{i} \int_{0}^{\omega}\left|f_{i}\left(u, x_{u}\right)\right| d u \\
& \geq \lambda A \int_{0}^{\omega}\left|f\left(u, x_{u}\right)\right| d u \geq \lambda A \eta\|x\| .
\end{aligned}
$$

Lemma 5. Assume that $\left(H_{1}\right)-\left(H_{3}\right)$ hold and let $r>0$, if there exists a sufficiently small $\epsilon>0$ such

$$
\begin{array}{r}
\int_{0}^{\omega}\left|f\left(s, \phi_{s}\right)\right| d s \leq \epsilon r, \quad \sum_{j=1}^{j=p}\left|I_{j}(\phi)\right| \leq \epsilon r, \\
\qquad \text { for } \phi \in K \cap \partial \Omega_{r} .
\end{array}
$$

Then,

$$
\|\Phi x\| \leq(\lambda+1) B \epsilon\|x\|, \quad \text { for } x \in K \cap \partial \Omega_{r} \text {. }
$$

Proof. For any $x \in K \cap \partial \Omega_{r}$,

$$
\begin{aligned}
\|\Phi x\|= & \sup _{t \in R} \sum_{i=1}\left|\left(\Phi_{i} x\right)(t)\right| \\
\leq & \sum_{i=1} \lambda B_{i} \int_{0}^{\omega}\left|f_{i}\left(s, x_{s}\right)\right| d s \\
& +\sum_{i=1} B_{i} \sum_{j=1}^{j=p}\left|I_{j}^{i}\left(x\left(\tau_{m_{j}}\right)\right)\right| \\
\leq & \lambda B \int_{0}^{\omega}\left|f\left(s, x_{s}\right)\right| d s \\
& +B \sum_{j=1}^{j=p}\left|I_{j}\left(x\left(\tau_{m_{j}}\right)\right)\right| \\
\leq & (\lambda+1) B \epsilon\|x\| .
\end{aligned}
$$

\section{Main Results}

For the sake of convenience, we introduce the following notations:

$$
\begin{aligned}
& f^{\alpha}=\lim _{x \in K} \sup _{\|x\| \rightarrow \alpha} \frac{\int_{0}^{\omega}\left|f\left(s, x_{s}\right)\right| d s}{\|x\|}, \\
& f_{\alpha}=\lim _{x \in K} \inf _{\|x\| \rightarrow \alpha} \frac{\int_{0}^{\omega}\left|f\left(s, x_{s}\right)\right| d s}{\|x\|}, \\
& I^{\alpha}=\lim _{x \in K} \sup _{\|x\| \rightarrow \alpha} \frac{\sum_{j=1}^{j=p}\left|I_{j}(x)\right|}{\|x\|}, \\
& I_{\alpha}=\lim _{x \in K} \inf _{\|x\| \rightarrow \alpha} \frac{\sum_{j=1}^{j=p}\left|I_{j}(x)\right|}{\|x\|},
\end{aligned}
$$

where $\alpha$ denotes either 0 or $\infty$.

Theorem 6. Assume that $\left(H_{1}\right)-\left(H_{3}\right)$ hold and

$$
\begin{aligned}
& \left(P_{1}\right) \quad f_{\infty}=\infty, \\
& \left(P_{2}\right) \quad f^{0}=I^{0}=0 ;
\end{aligned}
$$

then (3) has at least one positive w-periodic solution.

Proof. By $\left(P_{2}\right)$, for any $\epsilon_{1}, \epsilon_{1}>0$ there exists $r_{2}>0$, such that

$$
\begin{gathered}
\int_{0}^{\omega}\left|f\left(s, \phi_{s}\right)\right| d s \leq \epsilon_{1}\|\phi\| \leq \epsilon_{1} r_{2}, \\
\sum_{j=1}^{j=p}\left|I_{j}(\phi)\right| \leq \epsilon_{2}\|\phi\| \leq \epsilon_{2} r_{2} .
\end{gathered}
$$

Choose $\epsilon=\max \left\{\epsilon_{1}, \epsilon_{1}\right\}$, satisfying $0<\epsilon<(1 /(\lambda+1) B)$, by Lemma 5 , we have

$$
\begin{array}{r}
\|\Phi x\| \leq(\lambda+1) B \epsilon\|x\| \leq\|x\|, \\
\text { for } x \in K \cap \partial \Omega_{2} .
\end{array}
$$


Next, by $\left(P_{2}\right)$, there exists $r_{3}>r_{2}>0$, such that

$$
\begin{aligned}
& \int_{0}^{\omega}\left|f\left(s, \phi_{s}\right)\right| d s \geq \eta\|\phi\|, \\
& \quad \text { for } \phi \in K,\|\phi\| \geq r_{3},
\end{aligned}
$$

where $\eta>0$ is chosen, so that $\lambda A \eta>1$. It follows from Lemma 4 that

$$
\begin{array}{r}
\|\Phi x\| \geq \lambda A \eta\|x\|>\|x\|, \\
\text { for } x \in K \cap \partial \Omega_{3} .
\end{array}
$$

It follows from Lemma 3 that (3) has a positive $\omega$-periodic solution satisfying $r_{2} \leq\|x\| \leq r_{3}$.

Theorem 7. Assume that $\left(H_{1}\right)-\left(H_{3}\right)$ hold and

$$
\begin{aligned}
& \left(P_{3}\right) \quad f_{0}=\infty, \\
& \left(P_{4}\right) \quad f^{\infty}=I^{\infty}=0 ;
\end{aligned}
$$

then (3) has at least one positive $\omega$-periodic solution.

Proof. Since $f_{0}=\infty$, one can find an $r_{0}>0$, such that

$$
\begin{aligned}
& \int_{0}^{\omega}\left|f\left(s, \phi_{s}\right)\right| d s \geq \eta\|\phi\|, \\
& \text { for } \phi \in K, 0<\|\phi\| \leq r_{0},
\end{aligned}
$$

where $\eta>0$ is chosen so that $\lambda A \eta>1$. It follows from Lemma 4 that

$$
\begin{array}{r}
\|\Phi x\| \geq \lambda A \eta\|x\|>\|x\|, \\
\text { for } x \in K \cap \partial \Omega_{r_{0}} .
\end{array}
$$

By $\left(P_{4}\right)$, we know that there exists $N_{1}>r_{0}$ and $\epsilon_{1}, \epsilon_{2}>0$ such that

$$
\int_{0}^{\omega}\left|f\left(s, \phi_{s}\right)\right| d s \leq \epsilon_{1}\|\phi\|, \quad \sum_{j=1}^{j=p}\left|I_{j}(\phi)\right| \leq \epsilon_{2}\|\phi\|,
$$

for $\phi \in K,\|\phi\| \geq N_{1}$.

Choose $\epsilon=\max \left\{\epsilon_{1}, \epsilon_{1}\right\}$, satisfying $0<\epsilon<1 /(2(\lambda+1) B)$; then

$$
\int_{0}^{\omega}\left|f\left(s, \phi_{s}\right)\right| d s \leq \epsilon\|\phi\|, \quad \sum_{j=1}^{j=p}\left|I_{j}(\phi)\right| \leq \epsilon\|\phi\| .
$$

Take

$$
\begin{aligned}
r_{1}> & N_{1}+1 \\
& +2 B \sup _{\phi \in K,\|\phi\|<N_{1}}\left[\lambda \int_{0}^{\omega}\left|f\left(s, \phi_{s}\right)\right| d s+\sum_{j=1}^{j=p}\left|I_{j}(\phi)\right|\right],
\end{aligned}
$$

$$
\begin{aligned}
\|\Phi x\| & \leq B\left[\lambda \int_{0}^{\omega}\left|f\left(s, \phi_{s}\right)\right| d s+\sum_{j=1}^{j=p}\left|I_{j}(\phi)\right|\right] \\
& =B\left[\rho\left(I_{1}\right)+\rho\left(I_{2}\right)\right] \\
& \leq \frac{r_{1}}{2}+\frac{\|x\|}{2}=\|x\|, \quad \text { for any } x \in K \cap \partial \Omega_{r_{1}},
\end{aligned}
$$

where $\rho\left(I_{1}\right)=\left.\left[\lambda \int_{0}^{\omega}\left|f\left(s, \phi_{s}\right)\right| d s+\sum_{j=1}^{j=p}\left|I_{j}(\phi)\right|\right]\right|_{x \in I_{i}}, i=1,2$, and $I_{1}=\left\{x \in K,\|x\|<N_{1}\right\}, I_{2}=\left\{x \in K,\|x\| \geq N_{1}\right\}$.

This implies that $\|\Phi x\| \leq\|x\|$, for any $x \in K \cap \partial \Omega_{r_{1}}$.

Therefore, (3) has at least one positive $\omega$-periodic solution.

Theorem 8. Suppose that

$\left(P_{5}\right)$ there exists $d_{2}>0$, such that $\int_{0}^{\omega}\left|f\left(s, \phi_{s}\right)\right| d s<$ $d_{1} / \lambda A$, for $\sigma d_{1} \leq\|\phi\| \leq d_{1}$,

$\left(P_{6}\right)$ there exists $d_{2}>0$, such that $\int_{0}^{\omega}\left|f\left(s, \phi_{s}\right)\right| d s<$ $d_{2} / 2 \lambda B, \sum_{j=1}^{j=p}\left|I_{j}(\phi)\right| \leq d_{2} / 2 B$, for $\|\phi\|<d_{2}$

hold; then (3) has at least one positive w-periodic solution.

Proof. Without loss of generality, we may assume that $d_{2}<$ $d_{1}$. If $x \in K \cap \partial \Omega_{d_{2}}$, then by $\left(P_{6}\right)$, one can get

$$
\|\Phi x\| \leq \lambda B \frac{d_{2}}{2 \lambda B}+B \frac{d_{2}}{2 B}=d_{2}=\|x\|,
$$

in particular, $\|\Phi x\|<\|x\|$, for all $x \in K \cap \partial \Omega_{d_{2}}$.

On the other hand, by $\left(P_{5}\right)$, one has

$$
\begin{array}{r}
\|\Phi x\| \geq \lambda A \int_{0}^{\omega}\left|f\left(s, x_{s}\right)\right| d s>\lambda A \frac{d_{1}}{\lambda A}=d_{1}=\|x\|, \\
\text { for } x \in K \cap \partial \Omega_{d_{1}} .
\end{array}
$$

Therefore, (3) has at least one positive $\omega$-periodic solution.

Theorem 9. If

$$
\begin{aligned}
& \left(P_{7}\right) f^{0}=\alpha_{1} \in[0,1 / 2 \lambda B), I_{0}=\alpha_{2} \in[0,1 / 2 B) \\
& \left(P_{8}\right) f_{\infty}=\beta_{1} \in(1 / \lambda A \sigma, \infty)
\end{aligned}
$$

hold, then (3) has at least one positive w-periodic solution. 
Proof. By assumption $\left(P_{7}\right)$, for $\epsilon=\min \left\{(1 / 2 \lambda B)-\alpha_{1}, 1 / 2 B-\right.$ $\left.\alpha_{2}\right\}>0$, there exists a sufficiently small $d_{2}>0$ such that

$$
\begin{gathered}
\frac{\int_{0}^{\omega}\left|f\left(s, x_{s}\right)\right| d s}{\|x\|}<\alpha_{1}+\epsilon<\frac{1}{2 \lambda B}, \\
\frac{\sum_{j=1}^{j=p}\left|I_{j}(x)\right|}{\|x\|}<\alpha_{2}+\epsilon<\frac{1}{2 B}, \quad \text { for }\|x\| \leq d_{2} ;
\end{gathered}
$$

that is

$$
\begin{gathered}
\int_{0}^{\omega}\left|f\left(s, x_{s}\right)\right| d s<\frac{d_{2}}{2 \lambda B}, \\
\sum_{j=1}^{j=p}\left|I_{j}(x)\right|<\frac{d_{2}}{2 B}, \quad \text { for }\|x\| \leq d_{2} .
\end{gathered}
$$

So, $\left(P_{6}\right)$ is satisfied.

By assumption $\left(P_{8}\right)$, for $\epsilon=\beta_{1}-1 / \lambda A \sigma$, there exists a sufficiently large $d_{1}>0$ such that

$$
\frac{\int_{0}^{\omega}\left|f\left(s, x_{s}\right)\right| d s}{\|x\|}>\beta_{1}-\epsilon=\frac{1}{\lambda A \sigma}, \quad \text { for } \sigma d_{1} \leq\|x\| \leq d_{1},
$$

that is

$$
\int_{0}^{\omega}\left|f\left(s, x_{s}\right)\right| d s>\frac{1}{\lambda A \sigma}\|x\| \geq \frac{1}{\lambda A \sigma} \sigma d_{1}=\frac{d_{1}}{\lambda A},
$$

therefore, $\left(P_{5}\right)$ holds. By Theorem 8 , we complete the proof.

\section{Theorem 10. If}

$$
\begin{aligned}
& \left(P_{9}\right) f_{0}=\alpha_{3} \in(1 / \lambda A \sigma, \infty) ; \\
& \left(P_{10}\right) f^{\infty}=\beta_{2} \in[0,1 / 2 \lambda B), I_{\infty}=\beta_{3} \in[0,1 / 2 B)
\end{aligned}
$$

hold, then (3) has at least one positive $\omega$-periodic solution.

Proof. By $\left(P_{9}\right)$, for $\epsilon=\alpha_{3}-(1 / \lambda A \sigma)>0$, there exists a sufficiently small $d_{1}>0$, such that

$$
\frac{\int_{0}^{\omega}\left|f\left(s, x_{s}\right)\right| d s}{\|x\|}>\alpha_{3}-\epsilon=\frac{1}{\lambda A \sigma}, \quad \text { for } 0<\|x\| \leq d_{1},
$$

that is

$$
\int_{0}^{\omega}\left|f\left(s, x_{s}\right)\right| d s>\frac{\sigma d_{1}}{\lambda A}=\frac{d_{1}}{\lambda A}, \quad \text { for } \sigma d_{1} \leq\|x\| \leq d_{1} .
$$

Again, By $\left(P_{10}\right)$, for $\epsilon=\min \left\{(1 / 2 \lambda B)-\beta_{2},(1 / 2 B)-\beta_{3}\right\}>0$, there exists a sufficiently small $d>0$ such that

$$
\frac{\int_{0}^{\omega}\left|f\left(s, x_{s}\right)\right| d s}{\|x\|}<\beta_{2}+\epsilon, \quad \frac{\sum_{j=1}^{j=p}\left|I_{j}(x)\right|}{\|x\|}<\beta_{3}+\epsilon,
$$

that is

$$
\begin{array}{r}
\frac{\int_{0}^{\omega}\left|f\left(s, x_{s}\right)\right| d s}{\|x\|}<\frac{1}{2 \lambda B}, \quad \frac{\sum_{j=1}^{j=p}\left|I_{j}(x)\right|}{\|x\|}<\frac{1}{2 B}, \\
\text { for }\|x\|>d .
\end{array}
$$

In the following, we consider two cases to prove $\left(P_{6}\right)$ to be satisfied: (i) $\int_{0}^{\omega}\left|f\left(s, x_{s}\right)\right| d s+\sum_{j=1}^{j=p}\left|I_{j}(x)\right|<\infty$;

(ii) $\int_{0}^{\omega}\left|f\left(s, x_{s}\right)\right| d s=\infty, \sum_{j=1}^{j=p}\left|I_{j}(x)\right|=\infty$.

The bounded case is clear. If case (ii) is valid, then there exists $y \in B C\left(R, R_{+}^{n}\right),\|y\|=d_{2}>d$ such that

$$
\begin{gathered}
\int_{0}^{\omega}\left|f\left(s, x_{s}\right)\right| d s \leq \int_{0}^{\omega}\left|f\left(s, y_{s}\right)\right| d s, \\
\sum_{j=1}^{j=p}\left|I_{j}(x)\right|<\sum_{j=1}^{j=p}\left|I_{j}(y)\right|, \\
\quad \text { for } 0<\|x\| \leq\|y\|=d_{2} .
\end{gathered}
$$

Since $\|y\|=d_{2}>d$, then we have

$$
\begin{gathered}
\int_{0}^{\omega}\left|f\left(s, x_{s}\right)\right| d s<\frac{\|y\|}{2 \lambda B}=\frac{d_{2}}{2 \lambda B}, \\
\sum_{j=1}^{j=p}\left|I_{j}(x)\right|<\frac{\|y\|}{2 B}=\frac{d_{2}}{2 B}, \\
\text { for } 0<\|x\| \leq d_{2},
\end{gathered}
$$

which implies that condition $\left(P_{6}\right)$ holds. By Theorem 8 , we complete the proof.

Corollary 11. If one of the following pairs

$\left(P_{1}\right)$ and $\left(P_{2}\right) ;\left(P_{3}\right)$ and $\left(P_{4}\right) ;\left(P_{5}\right)$ and $\left(P_{6}\right) ;\left(P_{7}\right)$ and $\left(P_{8}\right) ;\left(P_{9}\right)$ and $\left(P_{10}\right)$;

$\left(P_{1}\right)$ and $\left(P_{7}\right) ;\left(P_{2}\right)$ and $\left(P_{8}\right) ;\left(P_{3}\right)$ and $\left(P_{10}\right) ;\left(P_{4}\right)$ and $\left(P_{9}\right)$

is valid, then system (3) has at least one positive $\omega$-periodic solution.

\section{Acknowledgments}

This research was supported by the National Nature Science Foundation of China (no. 11371027 and no. 11071001); Special Research Fund for the Doctoral Program of the Ministry of Education of China (no. 20123401120001); National Science Foundation of Educational Committee of Anhui Province of China (no. KJ2011B052); Program of Natural Science of Colleges of Anhui Province (no. KJ2013A032 and no. KJ2012A019).

\section{References}

[1] Y. Li and L. Zhu, "Positive periodic solutions for a class of higher-dimensional state-dependent delay functional differential equations with feedback control," Applied Mathematics and Computation, vol. 159, no. 3, pp. 783-795, 2004.

[2] X. Li and X. Lin, "Existence and multiplicity of positive periodic solutions to functional differential equations with impulse effects," Nonlinear Analysis: Theory, Methods \& Applications A, vol. 62, no. 4, pp. 683-701, 2005. 
[3] A. Wan, D. Jiang, and X. Xu, "A new existence theory for positive periodic solutions to functional differential equations," Computers \& Mathematics with Applications, vol. 47, no. 8-9, pp. 1257-1262, 2004.

[4] Z. Zeng, "Existence of positive periodic solutions for a class of nonautonomous difference equations," Electronic Journal of Differential Equations, vol. 3, pp. 1-18, 2006.

[5] J. S. Yu and B. G. Zhang, "Stability theorem for delay differential equations with impulses," Journal of Mathematical Analysis and Applications, vol. 199, no. 1, pp. 162-175, 1996.

[6] Y. Liu and W. Ge, "Stability theorems and existence results for periodic solutions of nonlinear impulsive delay differential equations with variable coefficients," Nonlinear Analysis: Theory, Methods \& Applications A, vol. 57, no. 3, pp. 363-399, 2004.

[7] W.-T. Li and H.-F. Huo, "Existence and global attractivity of positive periodic solutions of functional differential equations with impulses," Nonlinear Analysis: Theory, Methods \& Applications A, vol. 59, no. 6, pp. 857-877, 2004.

[8] Z. Zeng, L. Bi, and M. Fan, "Existence of multiple positive periodic solutions for functional differential equations," Journal of Mathematical Analysis and Applications, vol. 325, no. 2, pp. 1378-1389, 2007.

[9] N. Zhang, B. Dai, and X. Qian, "Periodic solutions for a class of higher-dimension functional differential equations with impulses," Nonlinear Analysis: Theory, Methods \& Applications $A$, vol. 68, no. 3, pp. 629-638, 2008.

[10] Z. Zheng, Theory of Functional Differential Equations, Anhui Education Press, Anhui, China, 1994.

[11] D. Guo, S. Jingxian, and L. Zhaoli, Functional Method of Nonlinear Ordinary Differential Equations, Scientific Press of Shandong, Jinan, China, 1995. 


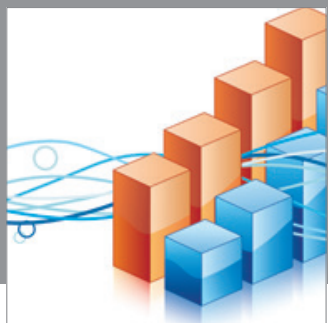

Advances in

Operations Research

mansans

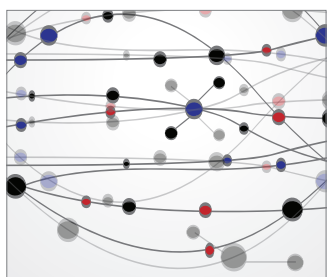

The Scientific World Journal
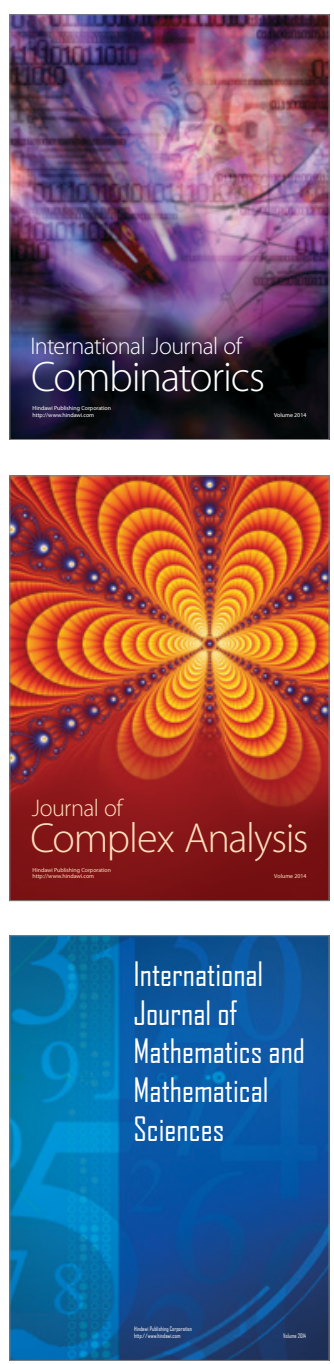
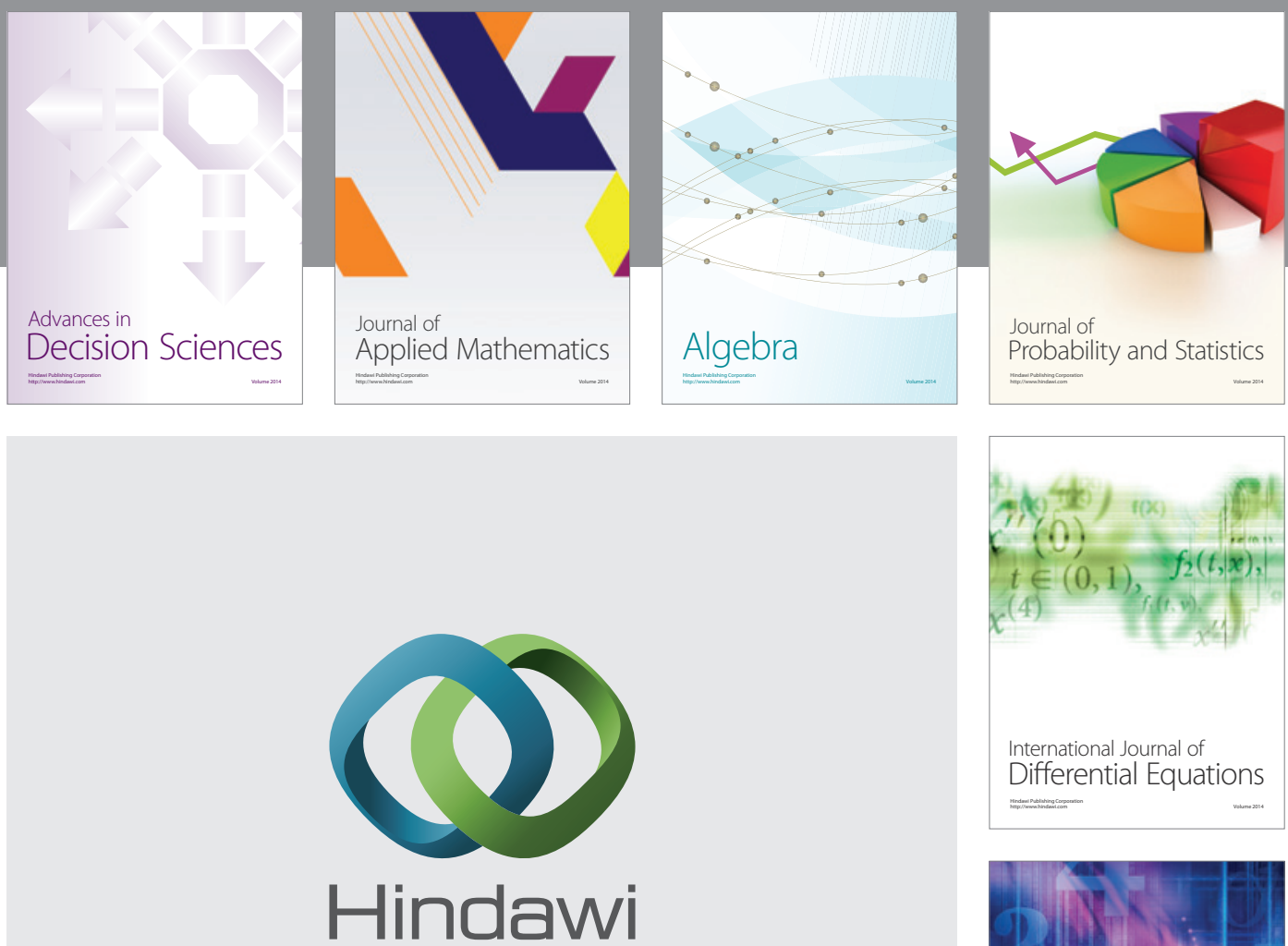

Submit your manuscripts at http://www.hindawi.com
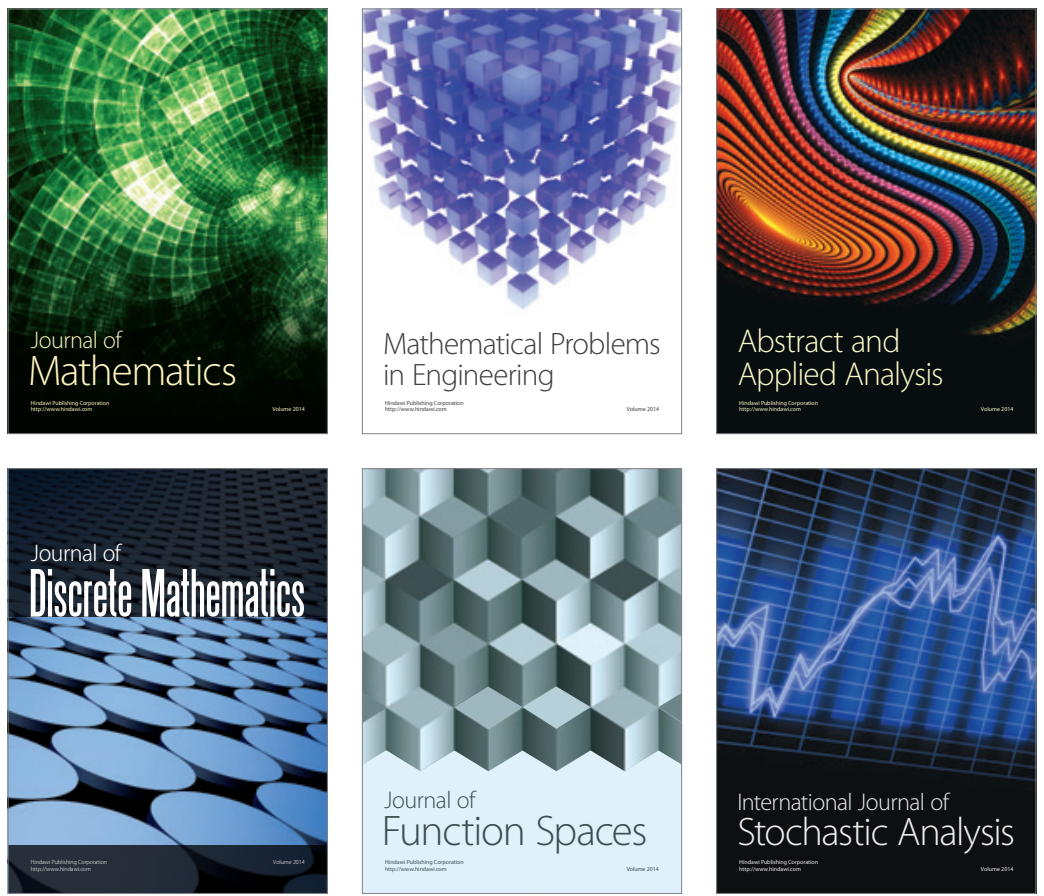

Journal of

Function Spaces

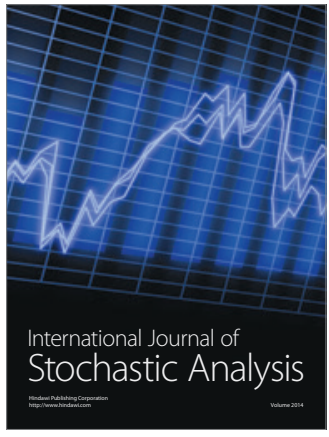

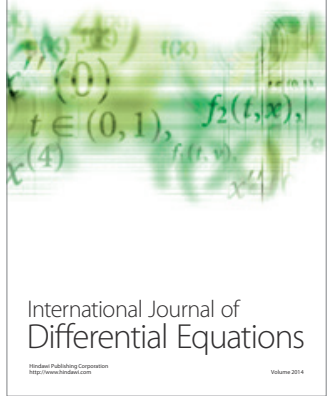
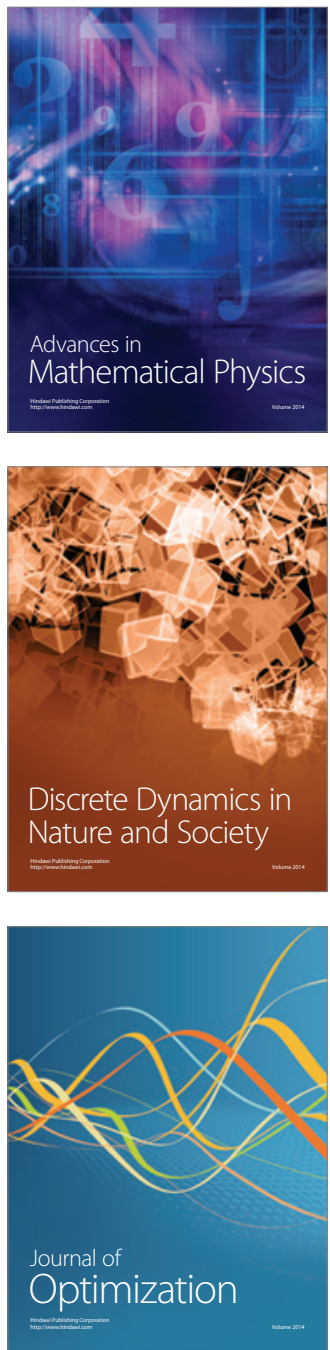